Arch. Met. Geoph. Biokl., Ser. B, 21, 157-174 (1973)

(C) by Springer-Verlag 1973

551.588 .2

Department of Geography, University of Windsor, Windsor, Ontario, Canada, and Department of Geography, University of Michigan, Ann Arbor, Michigan, U. S. A.

\title{
The Observation and Simulation of Diurnal Surface Thermal Contrast in an Alaskan Alpine Pass
}

\section{Anthony Brazel and Samuel I. Outcalt}

With 7 Figures

Received December 28, 1972

\section{Summary}

A simple surface climate simulator was employed in the analysis of thermal regimes in rough alpine terrain at Chitistone Pass, Alaska. The simulator favorably abstracts observations of thermal regimes on flat and sloping surfaces with variable thermal and radiative properties. It is shown that slope and exposure control variations in surface thermal regimes. The simulator predicts these controls and it is suggested that simulation of surface thermal regimes can be performed before and after field investigations, thus increasing the effective information content of thermal maps acquired using aircraft and orbital platforms. It is concluded that the removal by spatial filtering of the low frequency effects of slope and exposure on thermal maps is necessary before site material effects can be discriminated and analyzed.

\section{Zusammenfassung}

Beobachtung und Simulierung des Tagesganges der Bodentemperatur in einem alpinen Paß Alaskas

Ein einfaches Rechenmodell des Bodenklimas wurde auf die Analyse des Temperaturregimes im unebenen Terrain des Chitistone-Passes in Alaska angewandt. Das Modell bildet die beobachteten Temperaturregime ebener und geneigter Bodenflächen mit veränderlichen Wärmeleit- und Strahlungscharakteristiken zufriedenstellend $\mathrm{ab}$. Es wird gezeigt, daß Hangneigung und Hanglage im wesentlichen das Bodentemperaturregime bedingen. Das Modell sagt diese Bedingungsfaktoren richtig voraus. Es wird daher vorgeschlagen, daß Modellrechnungen vor und nach Feldmessungen angestellt werden sollten, um den effektiven Informationsgehalt der Temperaturverteilungskarten zu erhöhen, die von Flugzeugen 
oder Satelliten vermessen wurden. Es wird darauf hingewiesen, daß die Unterdrückung niederfrequenter Effekte von Hangneigung und Hanglage auf die kartographisch festgehaltene Temperaturverteilung notwendig ist, bevor Bodenbeschaffenheitseffekte diskriminiert und analysiert werden können. Diese Unterdrückung kann durch räumliche Filterung geschehen.

\section{Introduction}

The water content and the physical nature of the near surface soil is strongly reflected by the spatial variation of the phase and ampli-

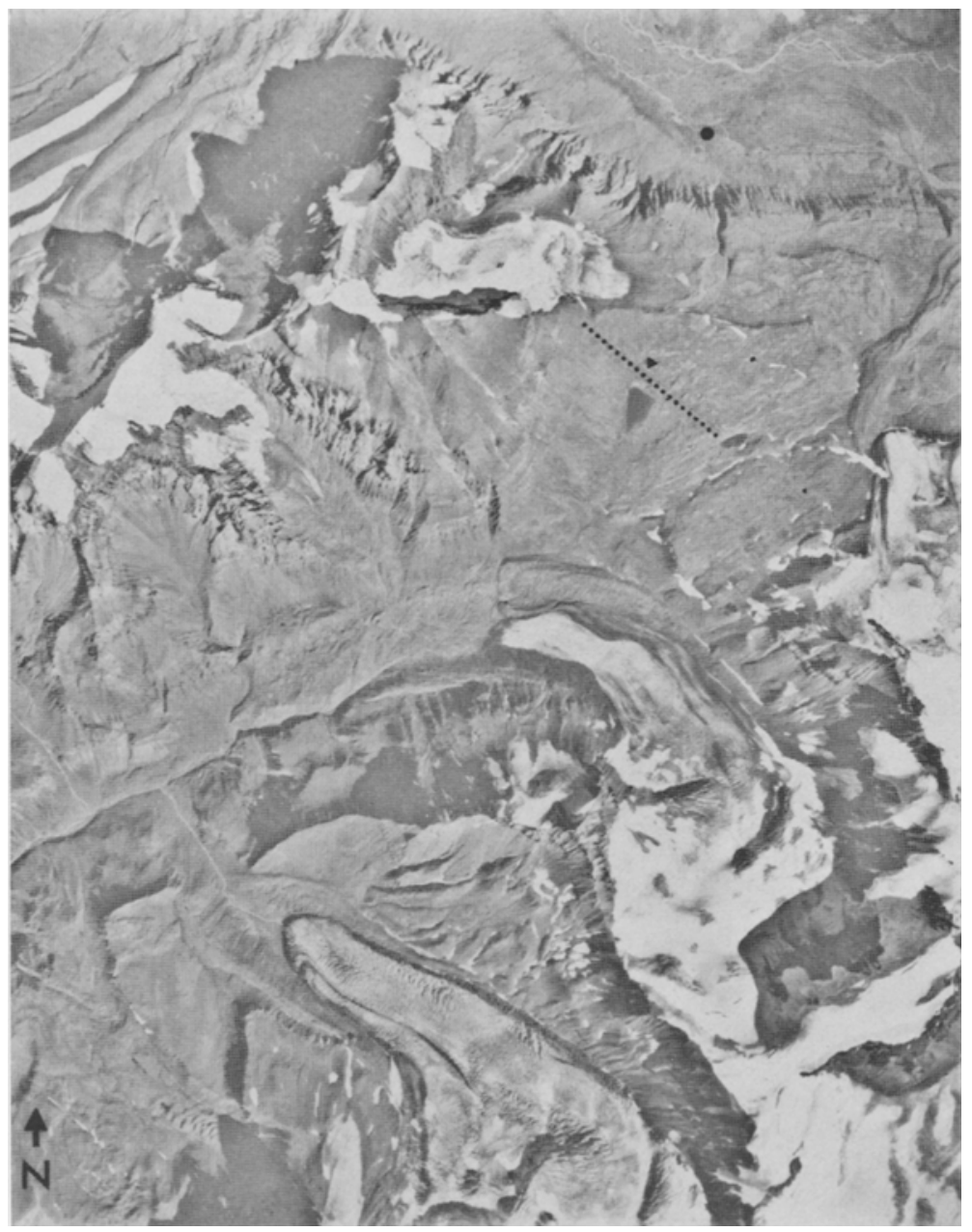

Fig. 1. Acrial photo of Chitistone Pass area (U. S. G. S.; August 15, 1957) Scale: $1 / 39,000$. 
tude of the surface thermal regime [7]. As the suitability of construction sites and the ability of men to move material overland is strongly governed by these conditions and their variability during the annual march of weather, sequences of thermal mapping during a diurnal clear weather cycle should yield valuable reconnaissance

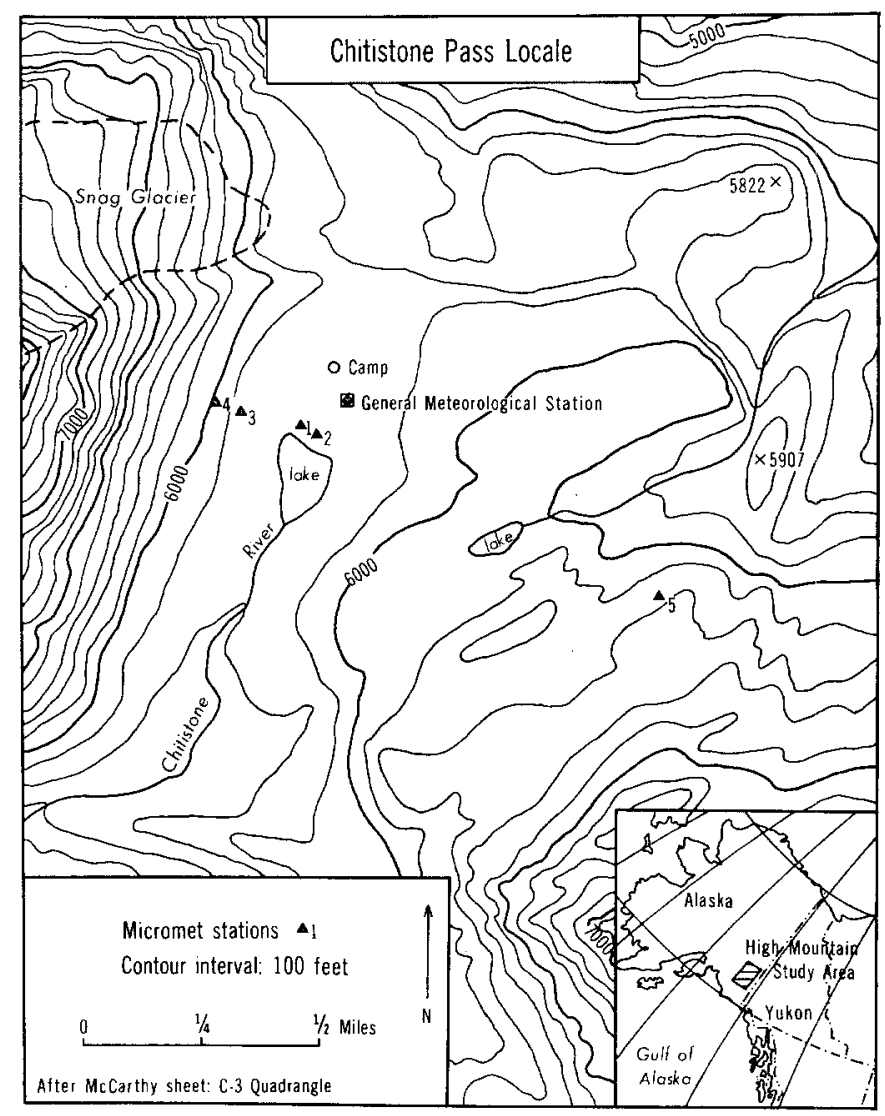

Fig. 2. Topographic map of the study region

information. However, in areas of high local relief these effects are masked by the effects of slope and exposure. It is thus of primary importance to demonstrate the degree to which these effects mask that portion of the surface thermal response produced by material variation. To this end field and simulation experiments have been carried out to examine the magnitude of these effects.

One of the purposes of the High Mountain Environment Project (HMEP), supported by the Arctic Institute of North America and 
160 A. Brazel et al.
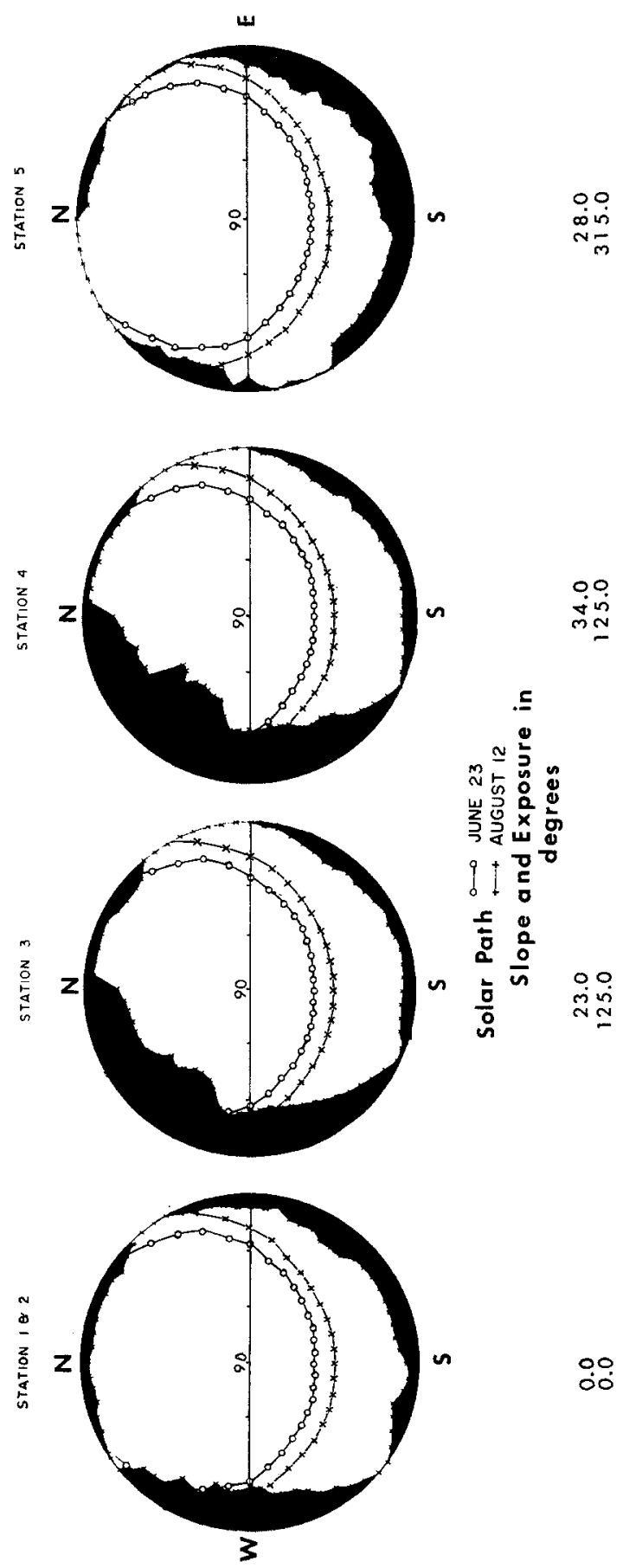

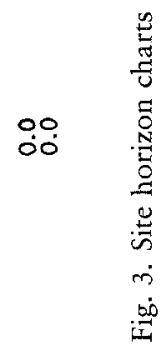


funded by the Army Research Office, Durham, North Carolina, was to investigate microclimate variations in alpine tundra terrain in 1967-1969 at Chitistone Pass, Alaska (see Figs. 1 and 2). Field data are available to investigate surface thermal regimes and simulation potentials for the task mentioned above.

Three types of climatic data were gathered at Chitistone Pass, Alaska: a) general three-hourly weather data from a first order station in the pass, b) microclimate data from five sites within the pass (see Fig. 2), and c) temperature data from thermographs placed in valleys and on slopes near the pass. The five microclimate sites were positioned at locations with varying topographic, radiative, and thermal conditions. Site horizons, slope angles, and exposures varied among the sites and are illustrated and listed in Fig. 3.

Thermal, topographic, and radiative properties of the five sites in the pass were investigated and were correlated with thermal regime behavior [2]. The observational findings are discussed below and provide ground truth information to compare with a surface temperature equilibrium model [8] in explaining thermal regime behavior for complex alpine terrain. The observational findings suggest a strong overriding slope and exposure control of the surface thermal regimes. The surface climate simulator indicates similar regime behavior and suggests that the simulation of surface thermal regimes can be performed before and after field investigations to increase the effective information content of thermal maps acquired using aircraft and orbital platforms.

\section{Observational Findings}

Investigations conducted at Chitistone Pass in 1967 and 1968 identified the relationships between site thermal regimes and environmental variables controlling them. These relationships are summarized considering the thermal regimes as responses to incident radiation and site property effects [2]. Six thermal characteristics were analyzed: a) surface diurnal mean temperature, b) surface diurnal temperature range, c) surface maximum temperature, d) $-10 \mathrm{~cm}$ soil diurnal mean temperature, e) $-10 \mathrm{~cm}$ soil diurnal temperature range, and f) $-10 \mathrm{~cm}$ soil diurnal maximum temperature. All temperatures were measured for 21 diurnal periods every 20 minutes with contact thermocouples manufactured by C. W. Thornthwaite Labs, Centerton, N. J. At all sites the surface and $-10 \mathrm{~cm}$ temperatures were recorded and at site 1,5 levels were observed in the active layer. 
The six responses for each of the five sites were compared with site properties. The site properties may be classified under three headings: a) thermal, b) radiative, and c) topographic. In the field study the specific properties under these three headings which were related to the five site's thermal regimes were [2]:

a) thermal: volumetric heat capacity, thermal diffusivity, depth to zero degree plane;

b) radiative: albedo, emissivity;

c) topographic: slope, exposure, site horizon, roughness length.

A rank correlation analysis indicated that the surface thermal regime is more sensitive to slope and exposure than site thermal and

Table 1. Spearman's Rho Rank Correlation of Thermal Regimes Versus Site Properties for Clear Weather

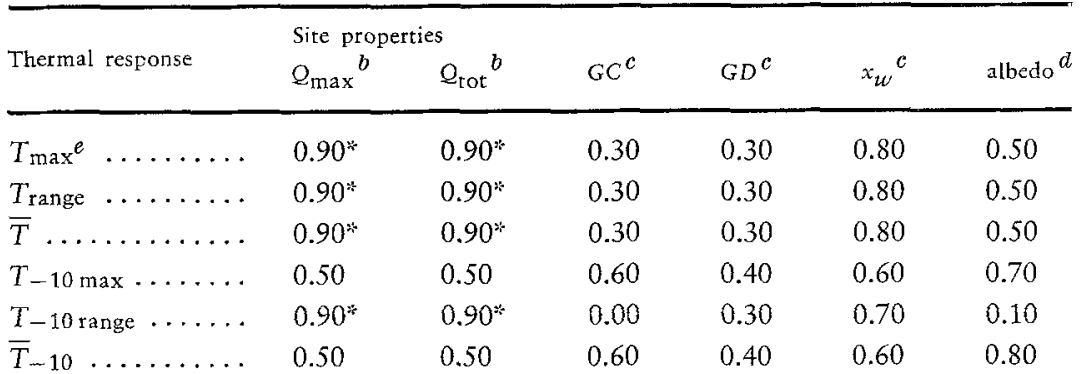

a The table is a matrix of correlation coefficients computed by the Spearman's Rho rank correlation technique. $T$ represents the surface temperature, and $T_{-10}$ the $-10 \mathrm{~cm}$ temperature.

b $Q_{\max }$ and $Q_{\text {tor }}$ are the maximum $\mathrm{ly} / \mathrm{min}$ and daily total solar radiation at the surface.

$c$ See text for how these properties were derived.

d Albedo is relative to the local surface. If on a slope, it is relative to the slope.

$e$ All temperatures measured with $\mathrm{Cu}$-Const thermocouples.

* Coefficients are significant at the $0.05 \%$ level.

N. B.: Site horizon, emissivity, and roughness length are not included. The error halo for emissivity and roughness length is equal to relative differences observed among the sites and hence these variables are not included in the analysis.

radiative property effects (see Tab. 1). Also, as indicated by Tab. 2, slope and exposure amplify thermal contrast in clear weather (note the large increases for $T_{\max }$ and $T_{\text {range }}$ for the slope stations).

The general results of this analysis suggest that slope and exposure override site property effects such as substrate heat capacity, thermal diffusivity, and moisture content. However, the rank correlation 
analysis and thermal regime data suggest secondary controls by these properties on terrain temperatures and also on substrate $(-10 \mathrm{~cm})$ temperatures.

To demonstrate the degree to which slope and exposure mask the site material effects, the surface climate simulator [8] can be employed. The model can be used to simulate thermal responses at

Table 2. Thermal Response to Changing Weather a

(Clear-Cloudy Day)

\begin{tabular}{lccl}
\hline Site & ${ }^{0}{ }^{\circ}$ & & \\
& ${ }^{T_{\max }{ }^{b}}$ & $T_{\text {range }}$ & $\bar{T}$ \\
\hline 1 & 6.6 & 6.2 & 3.2 \\
2 & 7.4 & 7.4 & 3.0 \\
3 & 10.2 & 8.7 & 3.6 \\
4 & 16.5 & 15.5 & 6.8 \\
5 & 8.0 & 8.4 & 3.8
\end{tabular}

$a$ For clear weather August 4, 1967 was used. For cloudy weather August 8, 1967 was used. For site 5 , the 9 th of July cloudly period and the 21 st of July clear period, 1968 were used.

$b T$ represents the surface temperature.

these five sites, given: a) all property effects (topographic, thermal, and radiative), and b) just the thermal and radiative effects (i. e., varying thermal diffusivity, moisture, heat capacity, and albedo) and allowing the sites to be abstracted onto a flat surface. In this manner, the magnitude of the masking effects of slope and exposure can be estimated. An additional task is to test the simulator in rough terrain. The structure of the simulator is sketched in the following section.

\section{The Climate Simulator}

The operation of the general simulator is based on the energy conservation equation which states that the four components of the energy budget (net radiation $R$, soil heat flux $S$, sensible heat flux $H$, and latent heat flux $L$ ) must have a zero sum across a surface:

$$
R+S+H+L=0 .
$$

Each of these terms is a complex function of the environmental variables which specify the thermal and radiative properties of the atmosphere and substrate media, and of the topographic effects at a location. At any instant in time, these components may be repre- 
sented as functions of a limited set of environmental variables and physical constants. These controlling variables are listed with their notation in Tab. 3.

Table 3. Environmental Input Variables

Station pressure $P$

Latitude $L A T$

Solar declination $D E C$

Dust particles $D$

Orbital radius vector $R$

Surface albedo

Precipitable water vapor $W$

Sky radiant temperature TSKY
Mean air temperature $T A$

Mean air relative humidity $R H$

Mean wind speed $U$

Soil thermal diffusivity $G D$

Soil vol. heat capacity $G C$

Surface roughness length $Z O$

Soil surface wetness $S R H$

The components of the energy budget equations can then be written in terms of these variables and the surface temperature $\left(T_{0}\right)$ as follows:

$$
R=f\left(L A T, D E C, D, R, A L B E D O, W, P, T S K Y, T_{0}\right) .
$$

If the assumption is made that the soil temperature at the diurnal damping depth is approximately equal to the mean air temperature then:

$$
S=f\left(G C, G D, T A, T_{0}\right) .
$$

The turbulent transfer terms which are corrected for stability using the Richardson Number may be expressed as:

$$
\begin{gathered}
H=f\left(U, Z O, P, T A, T_{0}\right), \\
L=f\left(U, Z O, P, R H, S R H, T A, T_{0}\right) .
\end{gathered}
$$

Note that in all of the above equations after specification of the input variables the surface temperature is the only unknown. The soil temperature profile is allowed to evolve by calculating a finite difference solution of the thermal diffusion equation using the soil thermal solution from the preceding step. After the new soil thermal profile is calculated the soil heat flux is actually calculated from the uppermost soil temperature level in place of TA.

At each step through the diurnal cycle the solar radiation incident on a surface may be calculated for a clear day by means of a subroutine. Subroutines are also included to calculate specific humidity gradients, to fix the free air computation level and correct the 
thermal properties of the atmosphere for stability. A sequence of approximations to the surface temperature are entered into the equation for the energy exchange until the equation approaches zero. The equilibrium surface temperature is that temperature which produces a suitably small residual in the energy balance equation (e. g., $1 \mathrm{mly} / \mathrm{min}$ ). Then all the components of the energy transfer regime $(R, S, H, L)$ and the soil temperature vector are equally close approximations and the next iteration begins with a forward solution of the finite difference form of the soil thermal diffusion equation.

A detailed account of the subroutines and assumptions in the simulator is available in the current literature [8]. The effects of variable stratigraphy were included in an advanced version of the simulator which is used in this study, by entering a thermal diffusivity value specific to each soil computation node. The effects of site slope and exposure were evaluated using methods described by Gates [4] and Kondrat'yev [6]. At each iteration the sun elevation was tested against the horizon elevation and the beam radiation incident at the site was weighed unity or zero accordingly in a manner similar to the treatment by Williams, et al. [10].

\section{The Application of the Simulator to Chitistone Data}

In order to compare the simulations with the Chitistone Pass observations, input variables which both generate and regulate the model must be specified. Tab. 4 shows the input values for each variable at each of the sites.

Slope and Exposure: The degree of slope at each of the sites was estimated by using a Brunton Compass and measuring the general slope, exposure (aspect), and site horizon angles for $10^{\circ}$ increments around the compass.

Roughness length estimates were made utilizing standard three-cup anemometers and calculating $\mathrm{ZO}$ for neutral adiabatic conditions. Average daily values are used in the model.

Surface albedo was measured with an upright and inverted Eppley 10-junction Pyranometer at each site. For sloping sites, the instrument was tilted relative to the slope.

Thermal Properties: The volumetric heat capacity was determined by measuring the partial fractions of organic $\left(x_{\theta}\right)$, mineral matter $\left(x_{m}\right)$, and moisture content $\left(x_{w}\right)$ (oven drying technique) in the 
Table 4. Input Variables for the Five Sites

\begin{tabular}{|c|c|c|c|c|c|}
\hline Variables & $\begin{array}{l}\text { Sites } \\
1\end{array}$ & 2 & 3 & 4 & 5 \\
\hline Slope (Deg) & 0.0 & 0.0 & 23.0 & 34.0 & 28.0 \\
\hline Exposure $(\operatorname{Deg}) \ldots \ldots$. & 0.0 & 0.0 & 125.0 & 125.0 & 315.0 \\
\hline$Z O(\mathrm{~cm}) \ldots \ldots \ldots \ldots$ & 2.0 & 0.2 & 5.0 & 2.0 & $(2.0)$ \\
\hline Albedo (fraction) ..... & 0.25 & 0.15 & 0.27 & 0.21 & $(0.18)$ \\
\hline Soil Fix. Depth $(\mathrm{cm}) \ldots$ & 55.0 & 75.0 & 150.0 & 150.0 & 150.0 \\
\hline$G D \cdot 10^{4}$ in cgs $\ldots \ldots$ & 34.0 & 150.0 & 48.0 & 17.0 & $(100.0)$ \\
\hline Soil $R H$ (fraction) ..... & 1.0 & 1.0 & 0.5 & 1.0 & $(0.2)$ \\
\hline Sites & $\begin{array}{l}\text { Soil layers } \\
Z(\mathrm{~cm})\end{array}$ & $G D \cdot 10^{4}$ & $G C$ & Descrip & \\
\hline 1 & $0-20$ & 34.0 & 0.61 & \multirow{2}{*}{\multicolumn{2}{|c|}{$\begin{array}{l}\text { organic coarse } \\
\text { sandy gravel } \\
\text { sandy clay }\end{array}$}} \\
\hline & $20-900$ & 37.0 & 0.46 & & \\
\hline 2 & $\begin{array}{c}0-11 \\
11-900\end{array}$ & $\begin{array}{r}150.0 \\
37.0\end{array}$ & $\begin{array}{l}0.72 \\
0.59\end{array}$ & \multicolumn{2}{|c|}{$\begin{array}{l}\text { sandy gravel } \\
\text { sandy clay }\end{array}$} \\
\hline 3 & $\begin{array}{c}0-20 \\
20-900\end{array}$ & $\begin{array}{l}48.0 \\
75.0\end{array}$ & $\begin{array}{l}0.61 \\
0.46\end{array}$ & \multicolumn{2}{|c|}{$\begin{array}{l}\text { organic-sandy clay } \\
\text { weathered basalt }\end{array}$} \\
\hline 4 & $\begin{array}{c}0-20 \\
20-900\end{array}$ & $\begin{array}{l}17.0 \\
75.0\end{array}$ & $\begin{array}{l}0.65 \\
0.46\end{array}$ & \multirow{2}{*}{\multicolumn{2}{|c|}{$\begin{array}{l}\text { organic-sandy clas } \\
\text { weathered basalt } \\
\text { basalt scree } \\
\text { weathered basalt }\end{array}$}} \\
\hline 5 & $\begin{array}{c}0-40 \\
40-900\end{array}$ & $\begin{array}{r}(100.0) \\
(75.0)\end{array}$ & $\begin{array}{l}(0.64) \\
(0.46)\end{array}$ & & \\
\hline
\end{tabular}

Constants for the Simulation:

Lat: $61.6^{\circ} \mathrm{N}$; Date (Mo. Day): $904.0(721.0)^{*}$; Emissivity: 0.98; Air Temp.: $7.4^{0} \mathrm{C}$ $\left(9.7^{0} \mathrm{C}\right)^{*}$; Air RH: $0.81(0.65)^{*}$; Wind: $200 \mathrm{~cm} / \mathrm{sec}(140 \mathrm{~cm} / \mathrm{sec})^{*}$; Ppt Water: 20.0 ; Dust: 0.20 ; Sky Rad. Temp.: $-12.6^{0} \mathrm{C}\left(-10.3^{\circ} \mathrm{C}\right)^{*}$; Air pressure: $835.0 \mathrm{mbs}$; Soil Fix. Temp.: $0.0^{\circ} \mathrm{C}$.

* Site 5 was not observed on August 4, but on July 21 - a clear day also. Simulation for that day is analyzed for site 5. Data used appear in parentheses above.

active layer at each site. These fractions were used in the following relationship to determine individual layer volumetric heat capacity:

$$
G C=G C_{m} x_{m}+G C_{o} x_{o}+x_{w}
$$

where $G C_{0}=0.60 \mathrm{cal} / \mathrm{cm}^{3 / 0} \mathrm{C}$, and $G C_{m}=0.46 \mathrm{cal} / \mathrm{cm}^{3 / 0} \mathrm{C}$.

These values are after Kersten [5] and de Vries [3]. Thermal diffusivity was determined by the following expression:

$$
G D=\frac{\omega}{2}\left[\frac{z_{2}-z_{1}}{\ln \delta_{1} / \delta_{2}}\right]^{2}
$$

where $G D=$ thermal diffusivity $\left(\mathrm{cm}^{2} / \mathrm{sec}\right), \omega=2 \pi / P$, where $P=$ 24 hours, $z_{1}=$ reference level 1 in the soil, $z_{2}=$ reference level 2 in 
the soil, $\delta_{1}=$ diurnal temperature amplitude at level $1, \delta_{2}=$ diurnal temperature amplitude at level $2, \mathrm{ln}=$ natural logarithm.

This method is only approximate since the assumption is made that the soil is homogeneous for the layer analyzed.

The soil wet fraction in the simulator is defined as the area fraction of the terrain immediately surrounding the site which is freely transpiring. For this study, the area wet fraction is considered equivalent to the area covered by tundra vegetation around the site and is only an approximate value.

Soil Thermal Fixing Depth: At each site the depth of the active layer was determined and monitored for the season. It has been demonstrated that variable active layer depth can influence the diurnal thermal regime if the variability is within the range of the diurnal damping depth of the thawed soil layer [7]. In this study, the days that were analyzed were mid-season to late season periods when the depth of the thawed layer was beyond the diurnal damping depth at all sites and showed no probable effect on the surface thermal regime.

Atmospheric Variables: Air temperature, relative humidity, wind speed and direction, and air pressure were measured at each microclimate site and at a central weather station in the pass. Generally spatial variations of these elements were minimal during the 21 diurnal periods, and thus for modeling purposes each site is assigned the same mean daily air temperature, relative humidity, wind speed, and air pressure value for the simulation.

Dust and Sky Radiant Temperature: In the solar radiation subroutine the dust index is set low at 0.20 which appears compatible with other studies for remote areas of this type [4]. Sky radiant temperature is arbitrarily set at $20^{\circ} \mathrm{C}$ below the mean air temperature as this approximation produced a clear sky net thermal radiation flux compatible with field observations.

\section{Simulation Results}

The simulator output for $R, S, H, L$, and $T_{0}$ is shown (as an example) along with $T_{0}$ observed for site 1 in Tab. 5. Figs. 4 and 5 illustrate the simulation of $T_{0}$ and comparison of $T_{0}$ 's for each site respectively. Amplitude and phase comparison between observed and simulated for each site are listed and ranked in Tab. 6. The results indicate no discrepancies in the amplitude ranking. The phase 
Table 5. Example of Simulation Output for Site 1, August 4, 1968

\begin{tabular}{lllrrrrrr}
\hline Time & $\begin{array}{l}\text { (lys/min) } \\
\text { Ex. Terr. } \\
\text { Radiation }\end{array}$ & $\begin{array}{c}\text { Absorbed } \\
\text { Sol. Rad. }\end{array}$ & $R$ & $S$ & $H$ & $L$ & \multicolumn{1}{c}{$T_{0 \text { sim }}$} & $T_{\text {Oobs }}$ \\
\hline 01 & & & -.09 & .04 & .04 & .01 & 3.2 & 4.5 \\
02 & & & -.09 & .04 & .05 & .01 & 3.1 & 4.0 \\
03 & & & -.09 & .03 & .05 & .01 & 3.0 & 3.5 \\
04 & .07 & .01 & -.09 & .03 & .05 & .01 & 3.1 & 3.8 \\
05 & .28 & .10 & -.01 & -.01 & .03 & -.01 & 4.8 & 5.5 \\
06 & .51 & .23 & .10 & -.06 & .00 & -.04 & 7.4 & 8.5 \\
07 & .74 & .36 & .22 & -.10 & -.03 & -.09 & 10.2 & 11.0 \\
08 & .95 & .50 & .33 & -.13 & -.06 & -.14 & 13.0 & 14.0 \\
09 & 1.13 & .62 & .43 & -.15 & -.09 & -.19 & 15.4 & 16.5 \\
10 & 1.27 & .71 & .51 & -.16 & -.11 & -.24 & 17.3 & 18.0 \\
11 & 1.36 & .77 & .56 & -.16 & -.12 & -.28 & 18.5 & 19.0 \\
12 & 1.39 & .79 & .57 & -.15 & -.13 & -.29 & 19.2 & 19.2 \\
13 & 1.36 & .77 & .55 & -.13 & -.13 & -.29 & 19.1 & 18.2 \\
14 & 1.27 & .71 & .50 & -.10 & -.12 & -.28 & 18.5 & 17.0 \\
15 & 1.13 & .62 & .42 & -.07 & -.11 & -.24 & 17.2 & 15.5 \\
16 & .95 & .50 & .31 & -.04 & -.09 & -.18 & 15.3 & 14.5 \\
17 & .74 & .36 & .20 & .00 & -.06 & -.14 & 13.0 & 11.2 \\
18 & .51 & .01 & -.11 & .11 & .02 & -.02 & 6.0 & 9.2 \\
19 & .28 & .01 & -.10 & .09 & .02 & -.01 & 5.2 & 7.5 \\
20 & .07 & .01 & -.10 & .07 & .03 & .00 & 4.6 & 6.5 \\
21 & & & -.10 & .07 & .03 & .00 & 4.1 & 5.5 \\
22 & & & -.10 & .06 & .04 & .01 & 3.8 & 5.0 \\
23 & & & -.10 & .05 & .04 & .01 & 3.6 & 5.0
\end{tabular}

The observed surface temperature is listed for comparison in the last column.

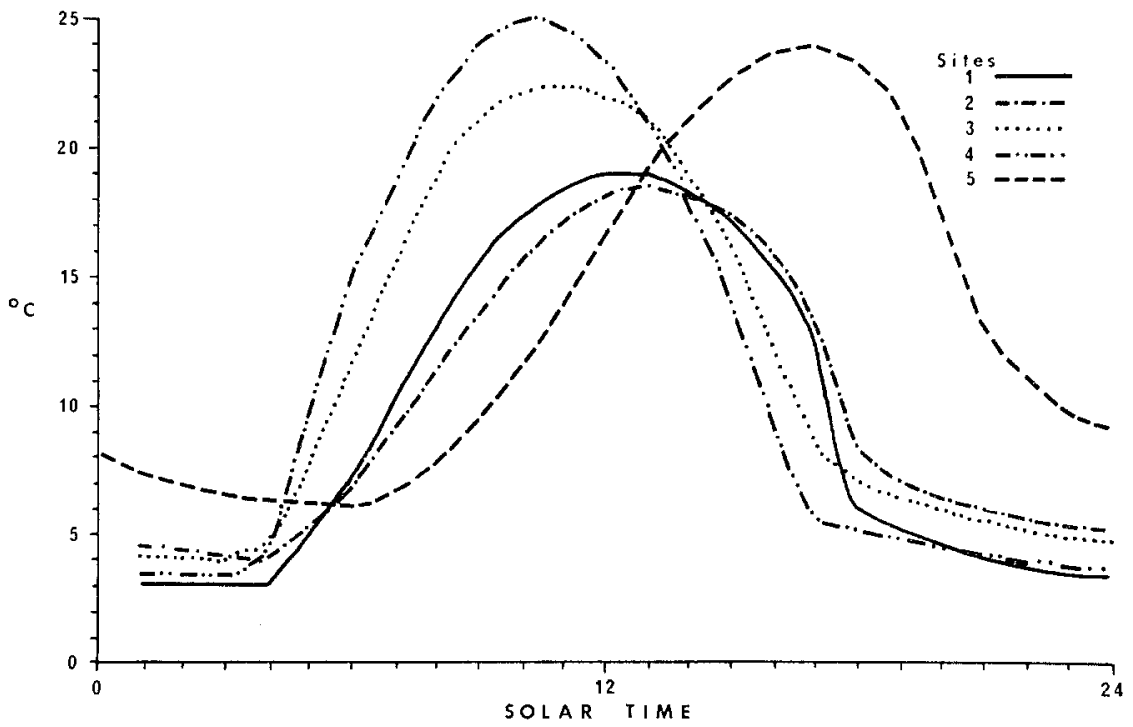

Fig. 4. Simulation of $T_{0}$ 
relationships are also ranked perfectly. Sources of minor discrepancies are discussed below. However, in general, the agreement is excellent.

Since the surface temperature is more difficult to observe and hence amalyze, the $-10 \mathrm{~cm}$ simulated and observed temperatures are
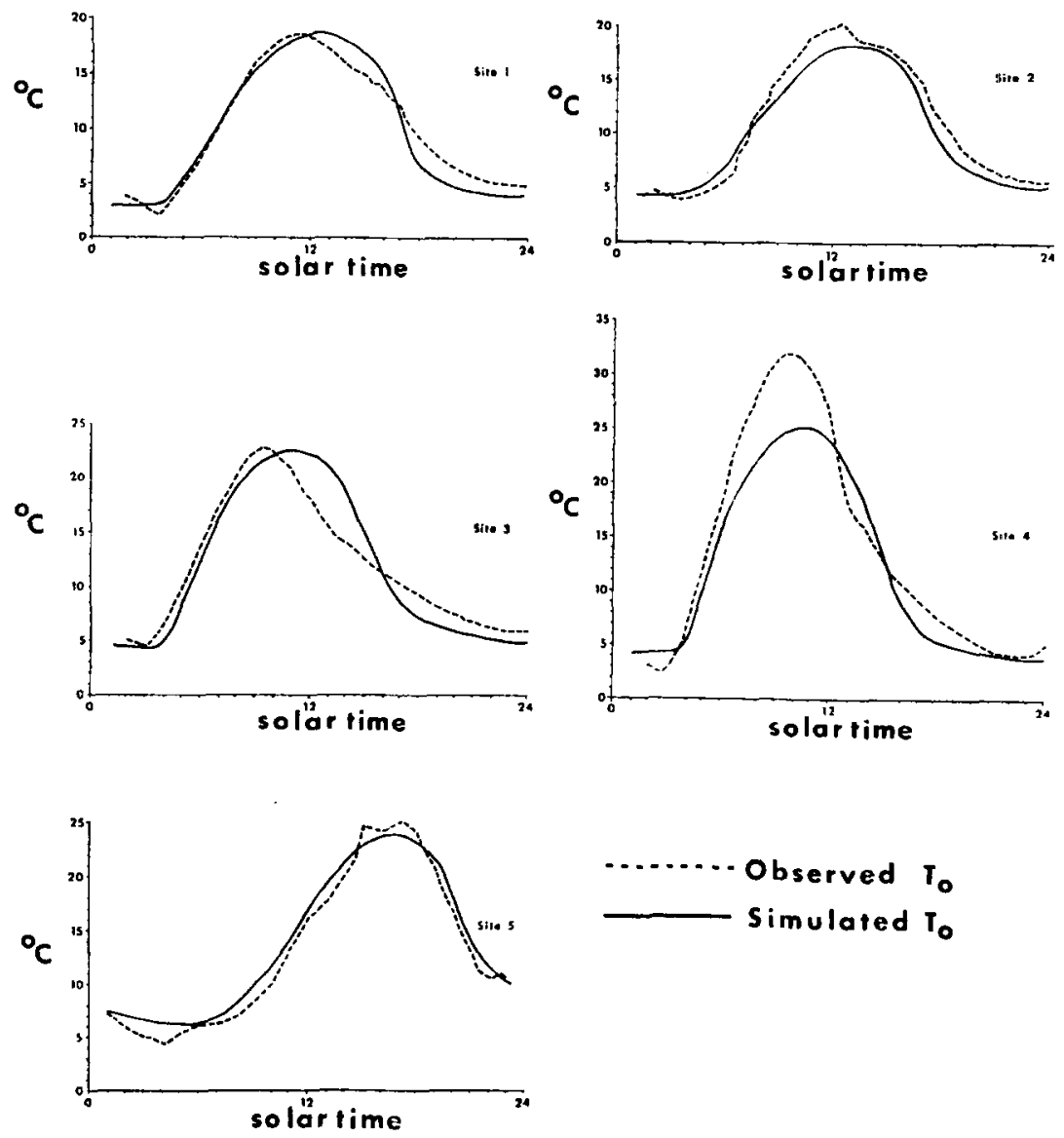

Fig. 5. Simulated and observed surface temperature

also ranked in terms of amplitude and phase in Tab. 6. Pictorial comparisons are shown in Fig. 6. There is a perfect ranking for the $-10 \mathrm{~cm}$ substrate temperatures.

The general results of the simulation analysis are encouraging; however, there are noticable errors obvious in the diagrams: for example, 
Table 6. Simulation and Observed Phase and Amplitude of Thermal Regimes of the Five Sites

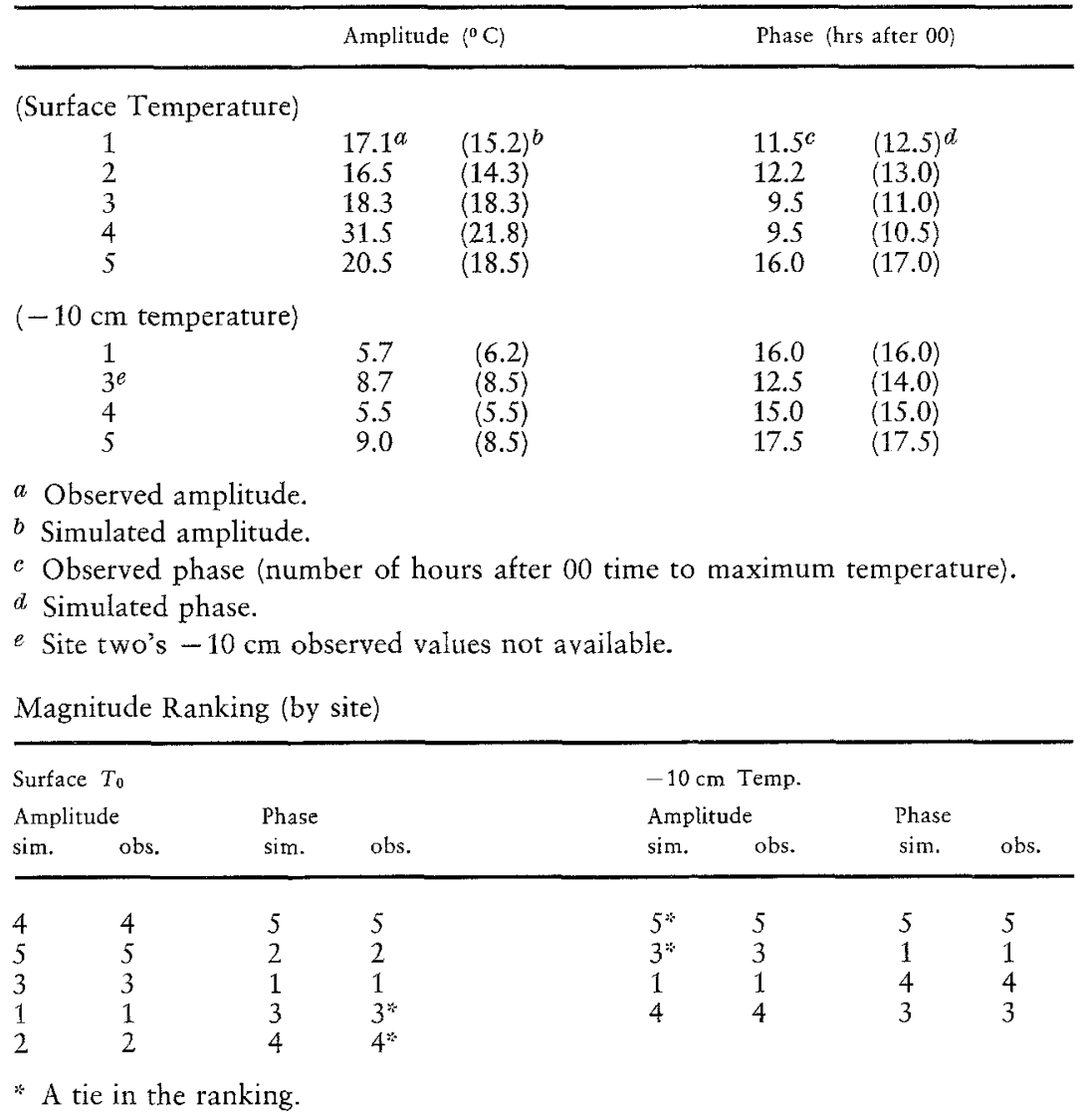

a) the better diurnal fit for the two flat sites compared with the other slope sites, and b) the high observed maximum temperature at site 4 .

\section{Sources of Probable Discrepancies for Surface Regime Simulation}

The fact that observed and simulated surface temperatures do not exactly match is probably related to at least four effects. The first is probable parametrization failure. For example, roughness length and thermal diffusivity are difficult to parameterize. In this study wind profile methods were used to estimate $Z O$ for each site. Also $G D$ was approximated by the standard temperature depth/amplitude ratio method suggested in Sellers [9]. 
The second is model failure. The simulator does not incorporate external effects that may be important to a local site's radiation balance (e. g., local effects on reflected radiation by microrelief variation nearby). The model furthermore utilizes mean daily wind
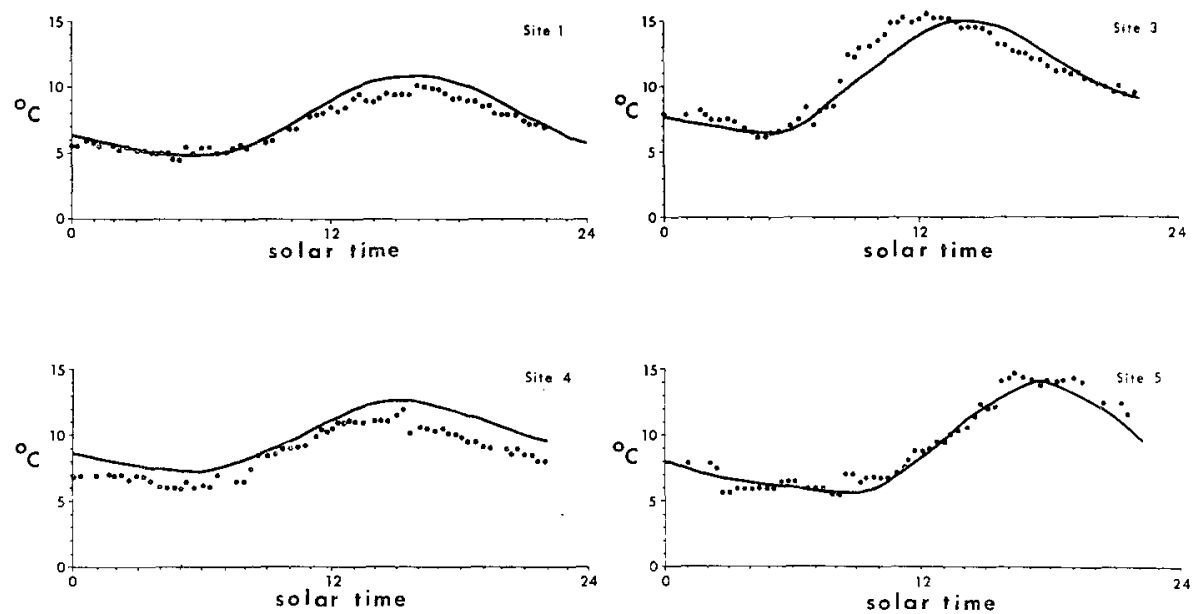

Observed

Simulated

Fig. 6. Simulated and observed $-10 \mathrm{~cm}$ temperature

speed, air temperature, relative humidity, and neglects spatio-temporal variations in these. Therefore, the model gives a generalized response pattern on a diurnal basis.

The third is the instrumental/measurement problem. Observation of the true surface temperature depends much on instrument placement at the surface. In this investigation a method followed by Ahrnsbrak [1] is used. The probe was placed in contact with the surface but made invisible from $1 \mathrm{~m}$ height above the ground. The fourth problem is advection. At present, the model does not incorporate advective effects.

These discrepancies should obviously be analyzed if model refining were to be important. However, the goal here is to examine the probable magnitude of thermal contrast and the major objective is to: a) predict optimum thermal mapping conditions, and b) rank the thermal contrast between sites. With this in mind, the simulator appears to perform adequately. 


\section{Magnitude Effects of Slope and Exposure}

Figs. 4 and 7 show the probable thermal regimes for clear weather with a) slope and exposure, thermal, and radiative properties as they are, and b) all five sites abstracted onto a flat surface and while retaining their specific thermal and radiative properties.

The "flat" simulation represents a thermal diurnal response of the terrain if topography could be eliminated as a variable. Fig. 4 represents the thermal pattern due to topography and site properties. Thermal patterns that are functions only of material parameters such as soil type, moisture variation, and active layer thickness are suitable targets for remote sensing. However, the thermal patterns are masked by slope and exposure (see sites 3, 4, and 5 diurnal curves for the "flat" and sloping simulations). The flat surface

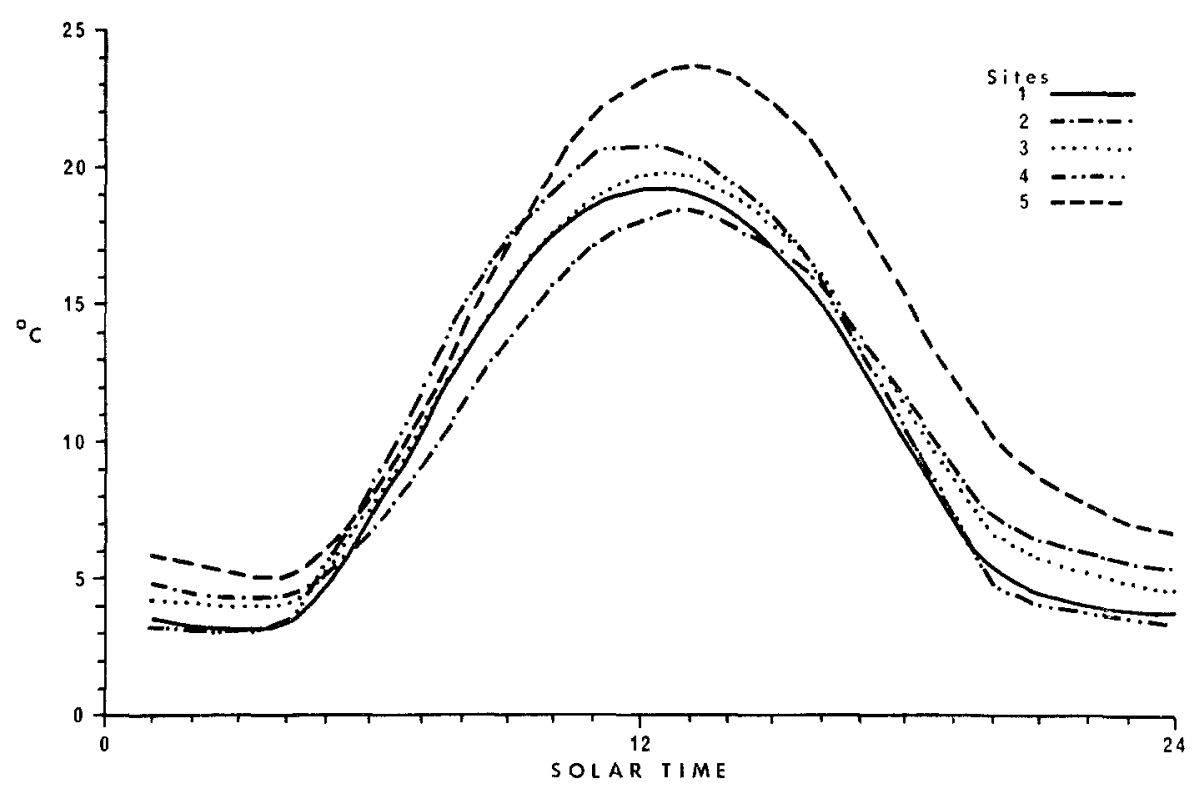

Fig. 7. Flat surface simulation of surface temperature

simulation indicates that scree slopes at site 5 would be readily identified by their warmer temperatures most of the day compared to the other sites. This certainly is not true in nature. Slope and exposure effects are considerable. Further, sites 3 and 4 versus 1 and 2 are vastly different between these simulations. The thermal and radiative properties of sites 1 and 2 compared to 3 and 4 would be 
poorly discriminated without filtering out the slope and exposure effects evident in Fig. 4 (compare it with Fig. 7).

The general results from the simulations suggest a significant effect of slope and exposure on the thermal regimes. Sites 3, 4, and 5 show a $5^{\circ} \mathrm{C}$ shift when slope and exposure are eliminated (or a shift of $20 \%$ of the overall amplitude). This is much larger than the relative differences among sites $1,2,3$, and 4 in the flat surface simulation (i. e., where only effects of thermal and radiative properties are considered).

\section{Conclusion}

There are two primary conclusions. First, it has been demonstrated that the surface climate simulator suitably abstracts observations at Chitistone Pass, Alaska. Secondly, manipulation of the simulator and an analysis of the thermal regime data both confirm the fact that there is a need to use spatial high frequency bypass filtering systems for the analysis of thermal and radiative properties of the terrain thermal response patterns. In this manner, topographic effects can be attenuated and important effects of site material properties amplified, as these are of prime importance to man.

\section{Acknowledgements}

The authors wish to express thanks to the Army Research Office, Durham, N. C., for making this paper possible by funding the research at Chitistone Pass, Alaska. Also appreciation is given to the Arctic Institute of North America for supporting the project through generous logistical assistance.

Special appreciation goes to Dr. Melvin G. Marcus, project leader of the High Mountain Environment Project, who guided the research stages of the Chitistone Pass investigations and gave invaluable time and guidance to Dr. Brazel.

\section{References}

1. Ahrnsbrak, W. F.: Summertime Radiation Balance and Energy Budget of the Canadian Tundra. Technical Report No.37. The University of Wisconsin. Department of Meteorology. 1968.

2. Brazel, A. J.: Active Layer Thermal Regimes in an Alpine Pass, Chitistone Pass, Alaska. Unpublished Ph. D. Dissertation. Department of Geography, University of Michigan, Ann Arbor, 1972.

3. Vries, A. de: The Thermal Behavior of Soils. Proc. Canberra Symposium Arid Zone Research Climatology and Microclimatology 11, 106-113 (1958).

4. Gates, D.: Energy Exchange in the Biosphere. New York: Harper and Row, Biological Monographs, 1962.

5. Kersten, M. S.: Thermal Properties of Soils. Engr. Expt. Sta. Bulletin, University of Minnesota, 1949. 
6. Kondrat'yev, K. Ya.: Radiative Heat Exchange in the Atmosphere. Pergamon Press (translated by O. Tedder, Oxford), 1955.

7. Outcalt, S. I.: The Simulation of Subsurface Effects on the Diurnal Surface Thermal Regime in Cold Regions. Arctic (in press).

8. Outcalt, S. I.: The Development and Application of a Simple Digital SurfaceClimate Simulator. J. Applied Meteorology 11, 629-636 (1972).

9. Sellers, W. D.: Physical Climatology. The University of Chicago Press, 1965.

10. Williams, L. D., R. G. Barry, and J. T. Andrews: Application of Computed Global Radiation for Areas of High Relief. J. Applied Meteorology 11, 526-533 (1972).

Authors' addresses: Prof. Dr. Anthony J. Brazel, University of Windsor, Department of Geography, Windsor, Ontario, Canada; Dr. Samuel I. Outcalt, University of Michigan, Department of Geography, Ann Arbor, MI 48104, U. S. A. 